\title{
ANALISIS SWOT TERHADAP PERPUSTAKAAN MAN 1 KOTA CIREBON DAN LITERASI PADA SISWA
}

\section{Rachmawati Suharaputri, Amelia Rahma Dwi Anjani, Taufik Ridwan}

Institut Agama Islam Bunga Bangsa Cirebon (IAI BBC) Jawa Barat Indonesia.

Email: rachmasuhara00@gmail.com ameliarahmadwi@gmail.com taufikridwan98@gmail.com

\begin{tabular}{|c|c|}
\hline & \\
\hline terima & \multirow{7}{*}{$\begin{array}{l}\text { Penelitian ini bertujuan untuk menganalisis pemanfaatan perpustakaan } \\
\text { sekolah di MAN } 1 \text { Kota Cirebon. Metode penelitian yang digunakan } \\
\text { adalah metode penelitian deskriptif, kualitatif. Berdasarkan analisis hasil } \\
\text { observasi dan didukung oleh dokumen-dokumen yang berkaitan dengan } \\
\text { penelitian ini bahwa pemanfaatan perpustakaan sekolah MAN } 1 \text { Kota } \\
\text { Cirebon ini bisa dikatakan relatif cukup baik. Hal ini terbukti dari } \\
\text { kunjungan siswa ke perpustakaan sekolah dan transaksi-transaksi } \\
\text { pemanfaatan perpustakaan dalam kurun waktu seminggu relatif cukup } \\
\text { baik. Hanya saja di era pandemic ini sedikit berbeda, aktivitas siswa pun } \\
\text { dibatasi dan tidak boleh bersama-sama ke perpustakaan, melainkan } \\
\text { bergantian dan secara bergiliran. Biasanya guru mata pelajaran akan } \\
\text { memberikan tugas untuk dikerjakan di perpustakaan, namun sekarang } \\
\text { karena pandemic siswa-siswa hanya datang untuk meminjam dan dibawa } \\
\text { pulang, tugas dikerjakan dirumah. }\end{array}$} \\
\hline & \\
\hline & \\
\hline & \\
\hline & \\
\hline & \\
\hline & \\
\hline
\end{tabular}

\section{ABSTRACT}

This research aims to analyze the utilization of school libraries in MAN 1 Cirebon City. The research methods used aredescriptive, qualitative research methods. Based on thelysis of observation results, and supported by documentsrelated tothis study that the utilization of the MAN 1 school library of Cirebon City can be said to be relatifquite good. This is evident from student visits to school libraries and library utilization transactions in the span ofa week isrelatively good. It's just that in this pandemic era a little different, student activities are limited and should not be together to the library, but alternately and in turn. Keywords: $\quad$ Usually the subject teacher will give assignments to be done in the Analysis, SWOT, library, but now because of the pandemic students only come to borrow Literacy and take home, the task is done at home.

\section{Pendahuluan}

Penyediaan fasilitas dan infrastruktur di sekolah sangat perlu, guna mencapai tujuan pendidikan nasional. Salah satu sarana dan prasarana yang ada ialah perpustakaan sekolah (Bafadal, 2001) menyatakan bahwa perpustakaan sekolah itu merupakan sumber belajar. Kegiatan yang paling tampak pada setiap kunjungan siswa adalah belajar, baik belajar masalah-masalah yang berhubungan langsung dengan mata pelajaran yang diberikan di kelas, maupun buku-buku lain yang tidak berhubungan langsung dengan mata pelajaran yang diberikan di kelas (Kusumaningrum et al., 2019). Penyelenggaraan perpustakaan sekolah, oleh (Bafadal, 2001) bukan hanya untuk mengumpulkan dan menyimpan bahan-bahan 
pustaka, tetapi dengan adanya penyelenggaraan perpustakaan sekolah diharapkan dapat membantu siswa dan guru menyelesaikan tugas-tugas dalam proses belajar mengajar.

Dalam dunia pendidikan khususnya, perpustakaan dijadikan sebagai sarana informasi yang diperlukan sebagai sumber belajar maupun laboratorium belajar yang memungkinkan para tenaga pendidik dan peserta pendidik meningkatkan kualitasnya (Rokan, 2017). Namun hal yang paling utama dalam mengoptimalkan fungsi perpustakaan adalah minat baca. Di perpustakaan sekolah siswa dapat mencari, menemukan, menjaring, dan menimba informasi sebanyak-banyaknya dari perpustakaan sekolah dengan mengikuti perkembangan ilmu pengetahuan dan teknologi (Sari, 2013). Perpustakaan sekolah merupakan sarana penunjang bagi kelangsungan kegiatan pembelajaran di sekolah, oleh karena itu kondisi ruang baca yang baik dan tenang, tentunya mempengaruhi minat berkunjung siswa, dan meningkatkan minat baca siswa, sehingga mempengaruhi hasil belajar yang dicapai siswa.

Menurut (Ibrahim, 2017) menyatakan "perpustakaan adalah ruangan, bagian dari sebuah gedung ataupun gedung itu sendiri yang digunakan untuk menyimpan buku atau terbitan lainnya yang biasanya disimpan menurut tata susunan tertentu untuk digunakan sebagai bahan bacaan bukan untuk dijual". Pengembangan perpustakaan sekolah menjadi keharusan dalam proses belajar sehingga menuntut guru dan siswa sama-sama aktif mencari informasi-informasi baru dari berbagai sumber informasi. Pemanfaatan perpustakaan mendapat perhatian pemerintah melalui undang-undang nomor 43 tahun 2007 pada pasal 3 menyatakan bahwa "perpustakaan berfungsi sebagai wahana pendidikan, penelitian, pelestrarian, informasi dan rekreasi untuk meningkatkan kecerdasan dan keberdayaan bangsa."
Berdasarkan uraian latar belakang diatas, melalui tulisan ini diharapkan dapat menambah cakarawala ilmu pengetahuan tentang manajemen perpustakaan yang dijadikan bekal untuk pengembangan perpustakaan ke depan.

\section{Metode Penelitian}

Metode penelitian yang digunakan dalam pemecahan permasalahan termasuk metode analisis, deskriptif, kualitatf (Cresswell, 2017). Sumber data yang digunakan dalam penelitian ini yaitu sumber data primer dan sumber data sekunder. Sumber data primer adalah sumber data yang diperoleh secara langsung melalui wawancara dengan informan yaitu 1 orang guru Pembina perpustakaan dan 1 orang petugas perpustakaan sekolah MAN 1 Kota Cirebon. Sebab menurut (Bungin, 2001) "Informan penelitian adalah subjek yang memahami informasi obyek peneliti”.

Sumber data sekunder adalah data yang diperoleh secara tidak langsung dalam penelitian yang terkait dengan pemanfaatan dan pengelolaan perpustakaan sekolah oleh siswa MAN 1 Kota Cirebon. Data ini diperoleh dari studi pustaka yang berupa buku-buku, referensi, dokumen dan hasil pengamatan penelitian yang berfungsi untuk melengkapi data primer. Teknik pengumpulan data pada penelitian ini adalah teknik observasi, wawancara dan studi dokumentasi.

Pertama teknik observasi peneliti melakukan pengamatan langsung terhadap bentuk pemanfaatan dan pengelolaan perpustakaan sekolah MAN 1 Kota Cirebon. Kedua teknik wawancara dilakukan kepada 1 orang guru Pembina perpustakaan, dan 1 orang petugas perpustakaan MAN 1 Kota Cirebon. Sebab Djam'an Satori dalam (Kurniati, 2011) menyatakan, "Studi dokumentasi yaitu mengumpulkan dokumen dan data-data yang diperlukan dalam permasalahan penelitian lalu ditelaah secara intens sehingga dapat mendukung dan 
menambah kepercayaan dan pembuktian suatu kejadian". Analisis data yang dilakukan pada penelitian ini, yaitu mengumpulkan data melalui observasi dan wawancara, memeriksa data yang sudah terkumpul, menganalisis data yang sudah diperoleh, selanjutnya untuk disimpulkan (Sugiyono, 2017).

\section{Hasil dan Pembahasan}

Penelitian ini dilaksanakan di perpustakaan MAN 1 Kota Cirebon. Pada tanggal 11-13 Oktober 2021. Data dari hasil penelitian yaitu pengumpulan datanya menggunakan observasi, wawancara berupa 22 item pertanyaan untuk guru Pembina perpustakaan, 7 item pertanyaan untuk petugas perpustakaan MAN 1 Kota Cirebon yang berkaitan dengan perpustakaan sekolah. Hasil analisis di perpustakaan sekolah diperoleh dari keterangan guru Pembina perpustakaan dan juga petugas perpustakaan serta keaktifan siswa dalam mencari bahanbahan referensi pelajaran. Pemberian tugas oleh guru mata pelajaran kepada siswa secara tidak langsung memberikan kesempatan kepada siswa untuk mencari penyelesaian dengan memanfaatkan buku-buku yang tersedia di perpustakaan sekolah.

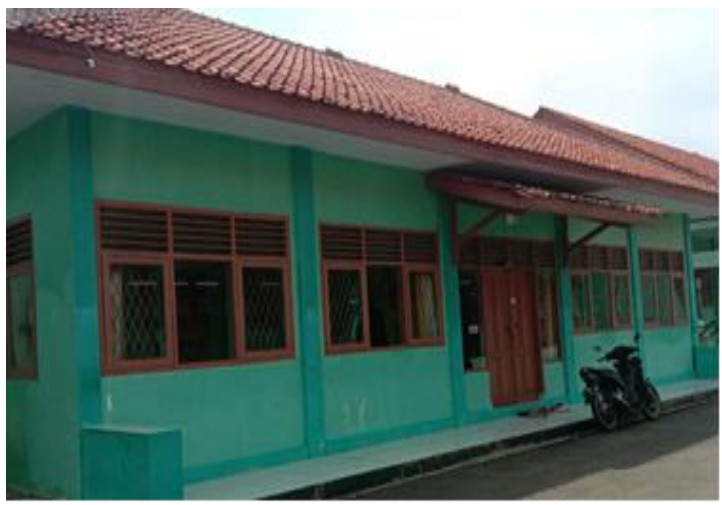

Gambar 1. Tampak Depan Perpustakaan

Tampak depan perpustakaan MAN 1 Kota Cirebon, di dalamnya terdapat berbagai jenis buku dan kondisi ruang baca yang sangat memadai. Diketahui bahwa frekuensi kunjungan siswa dengan kebiasaan belajar siswa dimana apabila kunjungan siswa keperpustakaan meningkat maka kebiasaan belajar siswa di perpustakaan juga akan meningkat. Artinya dengan semakin meningkatnya pemberian kunjungan maka kebiasaan belajara siswa di perpustakaan semakin tinggi, begitu juga sebaliknya.

Pemanfaatan perpustakaan sekolah dengan perkembangan belajar siswa, menunjukkan bahwa semakin sering siswa memanfaatkan perpustakaan memudahkan mereka untuk menemukan referensi untuk melengkapi materi ajar yang belum dipahami. mencari dan menyelesaikan permasalahan yang berkenaan dengan tugas-tugas dari guru (Hasmiati, 2017).

Perpustakaan MAN 1 Kota Cirebon belum menjadi perpustakaan digital, namun bias dikatakan Perpustakaan MAN 1 Kota Cirebon ini lebih baik disbanding dengan perpustakaan madrasah lainnya.

Desain ruang interior juga sangat mempengaruhi minat siswa terhadap perpustakaan. Desain interior dalam bangunan dibentuk oleh elemen-elemen yang bersifat arsitektur dari struktur pembentukannya yang terdiri atas ruangan, warna, cahaya, akustik suara, sirkulasi udara, aksesoris dan perabotan. Elemen-elemen tersebut membutuhkan pengembangan dengan cara memanipulasi elemen-elemen tersebut menjadi pola-pola spasial, visual dan sensori sehingga memperindah suatu ruangan dan membuatny dapat dihuni. Hal ini sesuai dengan minat anggota untuk melakukan aktivitas di ruang perpustakaan yang interiornya telah didesain menjadi lebih menarik.

Anggota yang berminat akan memiliki perasaan senang terhadap desain interior dan berkehendak untuk melakukan kegiatan di ruang perpustakaan, seperti membaca buku ataupun mengerjakan tugas. 


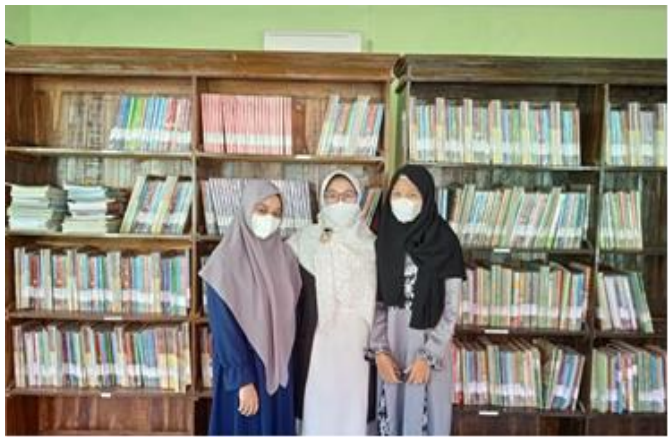

Gambar 2. Guru Pembina Perpustakaan

Poto diatas diambil bersama guru penjaga perpustakaan MAN 1 Kota Cirebon, beliau bernama ibu Yayu, yang juga merupakan salah satu guru mata pelajaran di MAN 1 Kota Cirebon.

Membership perpustakaan MAN 1 Kota Cirebon menggunakan kartu anggota perpustakaan, seluruh siswa wajib mempunyai kartu keanggotaan perpustakaan. MAN 1 Kota Cirebon mewajibkan siswa nya meminjam semua buku pelajaran berjumlah 21 buku, diantaranya, 5 buku agama, 4 buku peminatan, dan 12 buku pelajaran umum. Peminjaman ini dilakukan setiap tahun ajaran baru dan pengembaliannya dilakukan setiap akhir tahun ajaran.

Buku selain buku pelajaran dapat dipinjam dihari senin-kamis sesuai dengan jam buka perpustakaan. Buku yang sering dipinjam biasanya berupa novel ataupun fiksi, diperpustakaan MAN 1 Kota Cirebon juga terdapat koleksi kitab-kitab dan banyak buku referensi.

Tabel 1

Fasilitas Perpustakaan MAN 1 Kota Cirebon

\begin{tabular}{clcl}
\hline No & Nama Barang & No & Nama Barang \\
\hline 1 & Rak Buku & 4 & Komputer \\
\hline 2 & Meja dan Kursi Baca & 5 & Meja Penjaga \\
\hline 3 & AC & 6 & Karpet \\
\hline
\end{tabular}

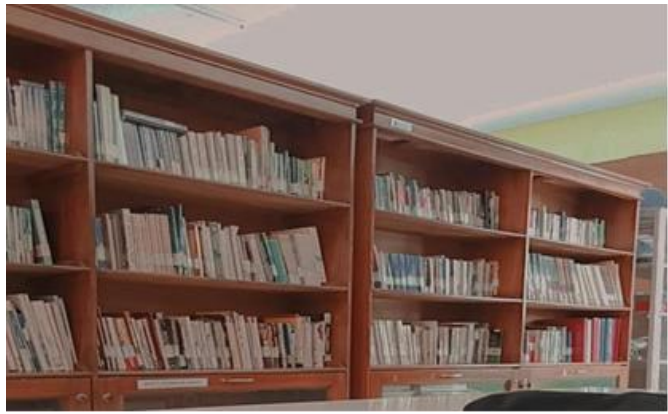

Gambar 3. Dalam Perpustakaan

Kondisi ruang baca perpustakaan MAN 1 Kota Cirebon memadai untuk siswa membaca buku di perpustakaan, meja baca yang besar cukup untuk sepuluh siswa membaca.

Biasanya untuk pembelajaran bahasa Indonesia guru kelas mengajak siswa-siswa nya untuk membaca diperpustakaan, dengan tujuan untuk meningkatkan minat baca siswa terhadap buku-buku.

Namun semenjak pandemic ini, siswa hanya ke perpustakaan sesekali dan itupun bergantian, sehingga pengunjung perpustakaan menurun. Siswa datang ke perpustakaan hanya untuk meminjam ataupun mengembalikan buku. Walaupun demikian perpustakaan MAN 1 Kota Cirebon masih dibuka, hanya saja waktu nya berbeda dengan yang sebelumnya. Jika sebelum pandemic buka pada pukul 07.00-15.00 WIB dan dimasa pandemic berkurang menjadi buka pada pukul 07.30-.12.00 WIB.

Pada penelitian ini membahas Analisis SWOT di perpustakaan Man 1 Kota Cirebon. Analisis SWOT merupakan sebuah strategi dalam dunia pendidikan untuk menyelidiki suatu peristiwa ataupun permasalahan dalam lembaga

Pendidikan 
Tabel 2

Hasil Analisis SWOT di Perpustakaan MAN 1 Kota Cirebon

\begin{tabular}{|c|c|c|c|}
\hline $\begin{array}{c}\text { Strength } \\
\text { (Kekuatan) }\end{array}$ & $\begin{array}{c}\text { Weakness } \\
\text { (Kelemahan) }\end{array}$ & $\begin{array}{c}\text { Opportunity (Kesempatan } \\
\text { atau Peluang) }\end{array}$ & $\begin{array}{l}\text { Threats (Tantangan } \\
\text { atau Ancaman) }\end{array}$ \\
\hline $\begin{array}{l}\text { 1. Fasilitas } \\
\text { memadai } \\
\text { dan } \\
\text { terdapat } \\
\text { ruang } \\
\text { baca yang } \\
\text { nyaman } \\
\text { dengan } \\
\text { adanya } \\
\text { fasilitas } \\
\text { ruangan } \\
\text { ber-AC. } \\
\text { Koleksi } \\
\text { bahan } \\
\text { pustaka } \\
\text { sesuai } \\
\text { dengan } \\
\text { jumlah } \\
\text { siswa dan } \\
\text { jumlah } \\
\text { mata } \\
\text { pelajaran } \\
\text { setiap } \\
\text { tingkatan } \\
\text { kelasnya } \\
\text { Petugas } \\
\text { perpustak } \\
\text { aan yang } \\
\text { sudah } \\
\text { cukup } \\
\text { memaha } \\
\text { mi } \\
\text { tugasnya } \\
\text { serta } \\
\text { memiliki } \\
\text { profesion } \\
\text { alisme } \\
\text { yang } \\
\text { baik. }\end{array}$ & $\begin{array}{l}\text { 1. Minimnya } \\
\text { tenaga } \\
\text { perpustakaa } \\
\mathrm{n} \text { dan } \\
\text { pemanfaata } \\
\mathrm{n} \text { teknologi } \\
\text { informasi . } \\
\text { 2. Minat baca } \\
\text { siswa yang } \\
\text { minim } \\
\text { hingga } \\
\text { perpustakaa } \\
\text { hanya } \\
\text { sebagai } \\
\text { tempat } \\
\text { peminjaman } \\
\text { dan } \\
\text { pengembali } \\
\text { an buku } \\
\text { mata } \\
\text { pelajaran. } \\
\text { Kurangnya } \\
\text { kesadaran } \\
\text { para guru } \\
\text { untuk } \\
\text { mengajak } \\
\text { muridnya ke } \\
\text { perpustakaa } \\
\text { n sebagai } \\
\text { rujukan } \\
\text { bahan ajar } \\
\text { selain buku } \\
\text { mata } \\
\text { pelajaran. }\end{array}$ & $\begin{array}{ll}\text { 1. } & \text { Pengadaan } \\
\text { teknologi untuk } \\
\text { meningkatkan } \\
\text { pelayanan } \\
\text { perpustakaan } \\
\text { sekolah. } \\
\text { 2. } \\
\text { mensosialisasikan } \\
\text { menariknya } \\
\text { koleksi } \\
\text { perpustakaan } \\
\text { untuk } \\
\text { meningkatkan } \\
\text { minat baca. } \\
\text { 3. } \\
\text { Kerjasama antar } \\
\text { guru } \\
\text { pelajaran mata } \\
\text { minat baca siswa } \\
\text { semakin tinggi } \\
\text { dan menjadikan } \\
\text { membaca sebagai } \\
\text { sebuah kebiasaan. }\end{array}$ & $\begin{array}{l}\text { 1. Perkembangan } \\
\text { teknologi } \\
\text { informasi } \\
\text { 2. Ketinggalan } \\
\text { teknologi } \\
\text { terbaru jika } \\
\text { perpustakaan } \\
\text { dan tenaga } \\
\text { perpustakaan } \\
\text { masih berkutat } \\
\text { dengan cara } \\
\text { lama. }\end{array}$ \\
\hline
\end{tabular}

\section{Kesimpulan}

Berdasarkan uraian diatas, penelitian di perpustakaan MAN 1 Kota Cirebon.

Kelebihan perpustakaan MAN 1 Kota Cirebon terdapat pada tempatnya yang luas dan memadai dan juga ruang baca sudah dilengkapi AC sehingga menambah kenyamanan bagi para siswa yang membaca diperpustakaan, koleksi buku nya pun banyak.

Kelemahan perpustakaan MAN 1 Kota Cirebon yaitu perpustakaan belum menggunakan system digital, dan semuanya dilakukan secara manual, namun untuk katalogisasi sesuai dengan standar katalogisasi 
nasional, serta jika tidak ada guru yang mengajak ke perpustakaan, jarang ada siswa yang datang, hanya siswa tertentu saja, oleh karena itu minat baca siswa masih sangat rendah.

Kerjasama antar guru dan siswa sangat diperlukan dan peran serta petugas perpustakaan untuk mengarahkan siswa nya agar sadar untuk membaca dan pentingnya membaca, seperti jadwal literasi tiap pagi hari dan diadakannya pojok baca di setiap kelas.

Pesan guru Pembina perpustakaan MAN 1 Kota Cirebon, ibu Yayu : "harapan kedepannya, perpustakaan MAN 1 Kota Cirebon bias mnjadi perpustakaan yang berbasis digital mengikuti perkembangan teknologi sekarang karena bias memudahkan siswa dan petugas perpustakaan, dan kartu keanggotaan perpustakaan menjadi satu dengan kartu siswa/kartu osis agar mengefesiensi kartu dan juga tidak mudah dihilangkan oleh siswa.

\section{Bibliografi}

Bafadal, I. (2001). Pengelolaan Perpustakaan Sekolah, Jakarta: Bumi Aksara. Jakarta: PT. Raja Grafindo Persada. Google Scholar

Bungin, B. (2001). Metodologi penelitian kualitatif. Google Scholar

Cresswell, J. W. (2017). Research Design: Pendekatan Kualitatif, Kuantitatif, dan Mixed (Edisi Ketiga). Pustaka Belajar. Google Scholar

Hasmiati, H. (2017). Persepsi Pemustaka tentang Pemanfaatan Perpustakaan Sekolah dalam Menunjang Proses Belajar Siswa SMPN 1 Sinjai Borong. Universitas Islam Negeri Alauddin Makassar. Google Scholar

Ibrahim, A. (2017). Pengantar Ilmu Perpustakaan dan Arsiparis. Google Scholar

Kurniati, E. (2011). Program bimbingan untuk mengembangkan keterampilan sosial anak melalui permainan tradisional. Surakarta: Skripsi Universitas Muhammadiyah Surakarta. Google Scholar

Kusumaningrum, D. E., Gunawan, I., Sumarsono, R. B., \& Triwiyanto, T. (2019). Pendampingan Pengelolaan Perpustakaan untuk Mendukung Gerakan Literasi Sekolah. Abdimas Pedagogi: Jurnal Ilmiah Pengabdian Kepada Masyarakat, 2(3), 164-169. Google Scholar

Rokan, M. R. (2017). Manajemen perpustakaan sekolah. Jurnal Iqra, 11(01). Google Scholar

Sari, M. (2013). Analisis Pemanfaatan Perpustakaan Sekolah oleh Siswa Kelas X Sman 1 Segedong pada Pembelajaran Sosiologi. Jurnal Pendidikan Dan Pembelajaran Khatulistiwa, 2(7). Google Scholar

Sugiyono. (2017). MetodePenelitian Kuantitatif, Kualitatif dan R\&D. Bandung: PT Alfabet. In Sugiyono. (2017). MetodePenelitian Kuantitatif, Kualitatif dan R\&D. Bandung: $P T$ Alfabet. Google Scholar

\section{Copyright holder :}

Rachmawati Suharaputri, Amelia Rahma Dwi Anjani, Taufik Ridwan (2020).

First publication right :

Action Research Literate

This article is licensed under:

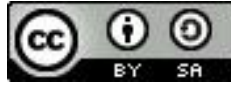

